\section{Article}

Doi 10.5943/mycosphere/6/6/8
ISSN 20777019

Mycosphere

Online Edition

\title{
Investigation of airborne fungi and their ability to grow on formalin- fixed human cadavers
}

\author{
Sri-indrasutdhi $\mathbf{V}^{1}$, Ueapattanakit $\mathbf{J}^{1}$ and Sommatas $\mathrm{A}^{2 *}$ \\ ${ }^{1}$ Fungal Biodiversity Laboratory, BIOTEC, National Science and Technology Development Agency (NSTDA), 113 \\ Thailand Science Park, Thanon Phahonyothin, Tambon Khlong Nueng, Amphoe Khlong Luang, Pathum Thani 12120, \\ Thailand \\ ${ }^{2}$ Department of Health Promotion, Faculty of Health Science, Srinakharinwirot University, $107 \mathrm{Mu}$ 6, Rangsit-Nakhon \\ Nayok Road, Ongkharak, Nakhon Nayok 26120, Thailand
}

Sri-indrasutdhi V, Ueapattanakit J, Sommatas A, 2015 - Investigation of airborne fungi and their ability to grow on formalin-fixed human cadavers. Mycosphere 6(6), 729-736, Doi 10.5943/mycosphere/6/6/8

\begin{abstract}
The problem of fungi growing on formalin-fixed human cadavers kept in the Gross Anatomy Laboratory at the Faculty of Health Science, Srinakharinwirot University (SWU) is reported after the flood subsided in 2011. This laboratory is located on the ground floor, with an entrance that is subject to the flow of outside air. It is suspected that airborne fungi may be the cause of those microbes growing on aforementioned cadavers. This study is to test the assumption that airborne fungi are the source of the contamination. Seventeen fungal species were identified with two unidentified aerial fungi. Two types of fungi were found growing on the formalin-fixed human cadavers and are different from those previously reported. In a previous study, it was reported that there were three types of fungi that could grow on formalin-fixed human cadavers within different types of environments and conditions. Certain environments can foster the growth of specific fungi on formalin-fixed human cadavers.
\end{abstract}

Key words - airborne fungi - contamination - flooding - formalin-fixed human cadaver Thailand

\section{Introduction}

Airborne fungi, the most important group in the air, have been well known as the cause of contamination problems in the environment and in human activities. Normally, fungi as saprophytes, play a significant role as primary decomposers of substrates in various ecosystems (Nazim et al. 2012). Some of them, nonetheless, are also parasitic in humans and animals (Samson et al. 2004). However, airborne fungi are involved in the respiratory system infections. For example, polypoid chronic rhinosinusitis has been caused by Bipolaris spicifera (Buzina et al. 2003), while Aspergillus fumigatus is associated with respiratory symptoms in patients with asthma (Fairs et al. 2013). Accordingly, the aeroallergen from Alternaria sp. is one of main factors causing allergy in human respiration (Cordon \& Millington 2001). Further, some groups of airborne fungi can grow inside office furniture and lead to exposure to volatile organic compounds (VOCs) or occupation-associated cancer epidemics due to aflatoxicosis (Gedikoglu et al. 2012). 
Air in various indoor environments contains fungal spores causing contamination when they colonize indoor substrates. In fact, air from outdoors may be the source of the spores whenever fresh air is introduced. Moreover, different indoor locations may serve as amplification sites for the growth or diversity of fungi. When appropriate humidity is available, spores can germinate and grow and produce numerous of new spores to use organic material in these places. Normally, airborne fungi can colonize and grow on many substrates and are worldwide in distribution (Hawksworth 1991).

Airborne fungi have become serious problems in Thailand which suffered from major flooding in northern and central regions from October to December in 2011. One of the main problems after the water level subsided was contamination of furniture, walls and furnishings by fungi. Most fungi came from dirty water that could not be immediately drained off causing increased humidity in enclosed buildings. We believe that they can grow and have a high potential to resist disinfectants or sanitizers on many substrates.

The Gross Anatomy Laboratory set up on the $1^{\text {st }}$ floor of Department of Health Promotion, Faculty of Health Science, Srinakharinwirot University (SWU) was one area subjected to flooding. This laboratory contained 12 formalin-fixed human cadavers for study and research. Although the Gross Anatomy Laboratory floor was not flooded, electricity and air-conditioners were shut down for approximately 70 days. Therefore, fungal spores germinated and grew on furniture, equipments and formalin-fixed human cadavers in this room. Although the fungal spores were mostly found on decayed wood, cloths, food, a few had potential to grow on dead animals and human cadavers (de Hoog \& Guarro 1995, Kwon-Chung \& Bennett 1992, Sharpton et al. 2009, Ishii et al. 2006). Nowadays, sources of fungal groups found on dead animals, human cadavers and formalin-fixed human cadavers remain unclear. Moreover, the majority of those fungi could not be identified to the species level (Lakchayapakorn et al. 2008, Kiyoshi et al. 2006). On the other hand, aerial fungi represent potential sources of those growing on formalin-fixed human cadavers that have not been reported. This study aims to investigate and study the fungal species from air and formalin-fixed human cadavers in the Gross Anatomy Laboratory, to compare the fungal abundance and to determine the fungal contaminants to species level by morphological and molecular techniques.

\section{Materials \& Methods}

\section{Air sampling and isolation}

Airborne fungi were randomly collected from the uncleaned Gross Anatomy Laboratory (6 $\times 8 \times 2.5 \mathrm{~m}$.) at the Department of Health Promotion, Faculty of Health Science, Srinakharinwirot University in February 2012 after the water level subsided, by non-volumetric air sampling method (Gams et al. 1998). Petri dishes of potato dextrose agar (PDA, Difco ${ }^{\mathrm{TM}}$ dehydrated culture media, Becton, Dickinson and Company, France) with added antibiotics (0.5 g/L streptomycin and chloramphenicol) were exposed to the indoor air (1 Petri dish per 1 square meter for 3 replications) for 15 minutes at room temperature (Flannigan 1997), then closed and placed into an incubator at $25^{\circ} \mathrm{C}$ at BIOTEC laboratory. After two days, the fungal colonies were observed and counted for calculated colony forming unit per cubic meter $\left(\mathrm{CFU} / \mathrm{m}^{3}\right)$. The different colonies were transferred to a new Petri dish, containing PDA medium with no antibiotics until we received an axenic cultures. All of Petri dishes were incubated at room temperature for 7 days.

\section{Isolation of formalin-fixed human cadavers}

The fungal mycelia were collected from two formalin-fixed human cadavers by the swab test technique. Sterile moistened cotton plugs have been used to pick up filamentous fungal mycelia and spores on cadavers and placed on PDA medium (Difco ${ }^{\mathrm{TM}}$ dehydrated culture media, Becton, Dickinson and Company, France). $0.5 \mathrm{~g} / \mathrm{L}$ of streptomycin and chloramphenicol were added to inhibit bacterial growth. After incubation at room temperature for 2 days, the fungal colonies were isolated to a new Petri dish as the same airborne fungi approach and checked for contamination up to 7 days. 


\section{Identification}

\section{Morphological study}

Morphological identification was made by preparing slide mounts in a few drops of sterile water, and then, fungal characters are classified under compound stereomicroscope (Olympus CX31) by considering of at least three characters on fungal colony. In addition, mycelia forms were checked weather a group of airborne fungi. Also, morphological characteristics, such as shape and size of conidia, conidiogenous cell and conidiophore, were examined. Moreover, special various characters were demonstrated and compared with the known species in taxonomic keys. Malt extract agar (Bacto $^{\mathrm{TM}}$ dehydrated culture media, Becton, Dickinson and Company, France) and Czapek solution agar Difco $^{\mathrm{TM}}$ dehydrated culture media, Becton, Dickinson and Company, France) were used to compare the different fungal colony characters for 7 days.

\section{Molecular identification}

Airborne fungi and fungal isolated from formalin-fixed human cadavers were cultured on PDA for 7 days at room temperature. The growing mycelia were scrape off the surface of a colony and transferred to $2 \mathrm{ml}$ eppendorf micro-centrifuge tubes. The DNA extraction was used the CTAB protocol and purity the genomic DNA according to the procedures in Sri-indrasutdhi et al. 2015. Two loci i.e. Internal Transcribed Spacer (ITS) rDNA and partial $\beta$-tubulin region were used for PCR amplification. The PCR products were sequenced by Macrogen Inc., Republic of Korea, with the same PCR primers. The nucleotide sequences were compared using BLAST search in the National Center for Biotechnology Information (NCBI) program (data not shown).

\section{Results}

\section{Fungal species found in the Gross Anatomy Laboratory}

Seventeen strains of airborne fungi were isolated on agar medium from the Gross Anatomy Laboratory. They belong to 11 genera, 15 species and 2 unidentified fungi while average number of taxa per Petri dish was 6.2. As a result, filamentous fungi isolated are listed in Table 1. The finding indicated that Penicillium species were the most common with four species: Penicillium calidicanium, P. oxalicum, P. verruculosum and Penicillium sp., with two Aspergillus species: Aspergillus japonicus, A. niger. Alternaria solani, Cladosporium colocasiae, Diaporthe sp., Hyphodermella corrugate, Hypocrea lixii, Peniophora sp., Phlebiopsis gigantean, Pseudocercospora pallida and Trichoderma atroviride were also recorded. Moreover, Trichoderma atroviride and Cladosporium colocasiae show the most abundance $\left(9.4 \times 10^{6}\right.$ and $9.1 \times 10^{6}$ $\mathrm{CFU} / \mathrm{m}^{3}$ )

\section{Fungal species found on the formalin-fixed human cadavers}

For the formalin-fixed human cadavers, different fungal mycelium was found growing on two cadavers. The first colony was found on the thumb and middle finger of right foot (Fig. 1c). Characteristic features of these colonies are white mycelium, bunched together. Another colonies were found on the neck and chin muscle of the cadaver (Fig. 1d). Characteristic features of colony are pale green to yellow green mycelium, short with eruption of the skin. Two colonies were isolated to pure cultures, prepared slides and identified by morphological features, and confirmed by using Internal Transcribe Spacer (ITS) regions of the ribosomal DNA genes and partial $\beta$ tubulin sequences (data not shown). Results of BLAST sequence comparisons have shown that the two isolates were identified as Penicillium oxalicum and Cladosporium colocasiae, with 100\% sequence identity. 
Table 1 List of fungal species found and concentration from the Gross Anatomy Laboratory.

\begin{tabular}{llc}
\hline Isolate Code & \multicolumn{1}{c}{ Scientific Name } & Concentration $\left(\mathbf{C F U} / \mathbf{m}^{3}\right)$ \\
\hline ASP00740 & Alternaria solani & $7.8 \times 10^{5}$ \\
ASP00754 & Aspergillus japonicus & $5.3 \times 10^{6}$ \\
ASP00766 & Aspergillus niger & $6.3 \times 10^{6}$ \\
ASP00586 & Cladosporium colocasiae & $9.1 \times 10^{6}$ \\
ASP00735 & Diaporthe sp. & $5.7 \times 10^{4}$ \\
ASP00745 & Hyphodermella corrugata & $5.6 \times 10^{3}$ \\
ASP00761 & Hypocrea lixii & $5.2 \times 10^{4}$ \\
ASP00744 & Penicillium calidicanium & $8.8 \times 10^{4}$ \\
ASP00749 & Penicillium oxalicum & $4.5 \times 10^{5}$ \\
ASP00743 & Penicillium sp. & $3.8 \times 10^{5}$ \\
ASP00768 & Penicillium verruculosum & $5.0 \times 10^{4}$ \\
ASP00741 & Peniophora sp. & $8.6 \times 10^{3}$ \\
ASP00584 & Phlebiopsis gigantea & $6.4 \times 10^{5}$ \\
ASP00772 & Pseudocercospora pallida & $7.6 \times 10^{4}$ \\
ASP00748 & Trichoderma atroviride & $9.4 \times 10^{6}$ \\
ASP00736 & Unidentified 1 & $4.2 \times 10^{4}$ \\
ASP00737 & Unidentified 2 & $6.3 \times 10^{4}$ \\
\hline
\end{tabular}
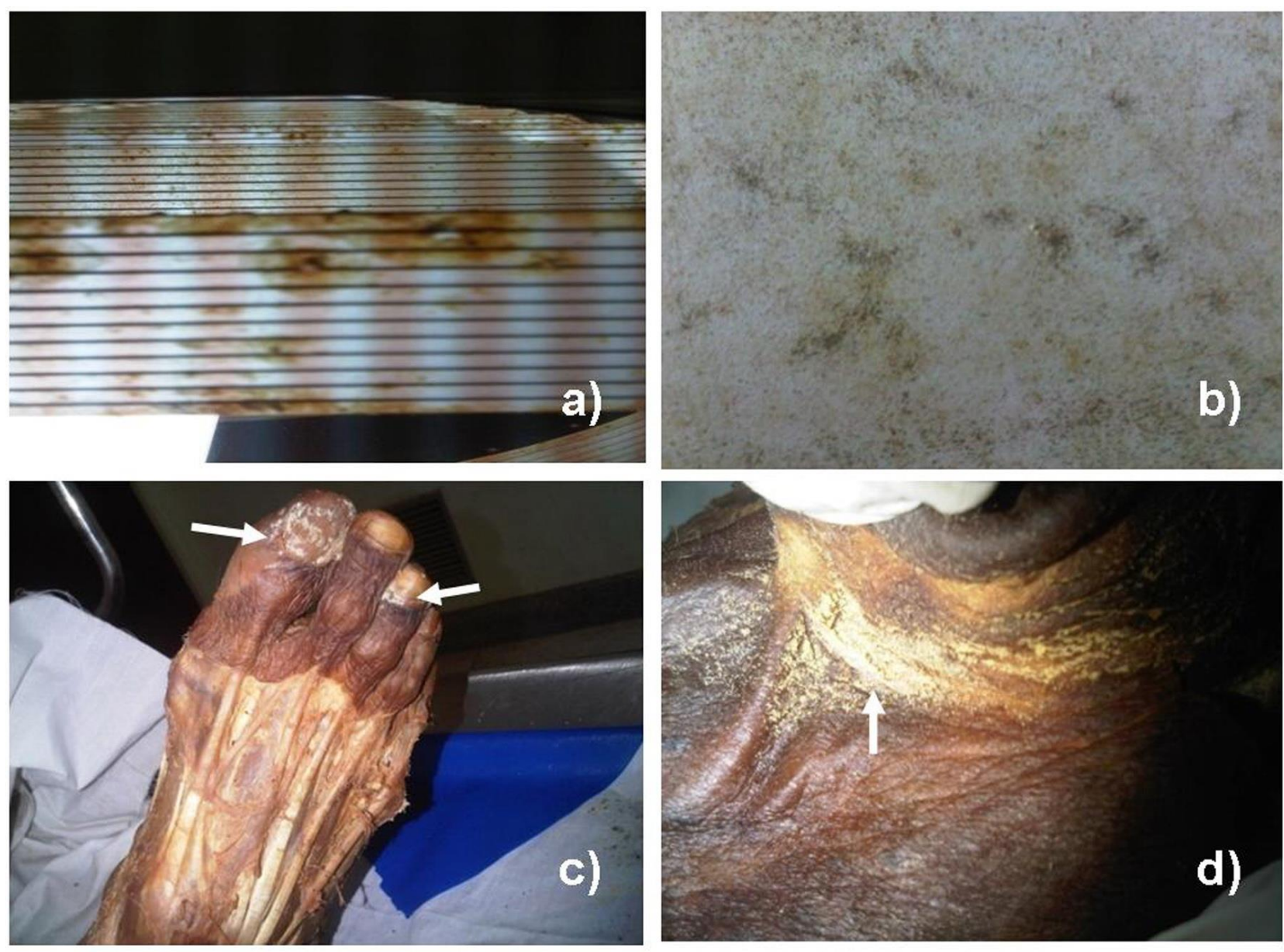

Fig. 1 - Characteristic of filamentous fungal colonies found on two formalin-fixed human cadavers at the Gross Anatomy Laboratory. a) On the thumb and the middle finger of the cadaver's right foot (arrow). b) On the neck and shin muscle of cadaver. 


\section{Morphological description}

Penicillium oxalicum Currie \& Thom, Journal of Biological Chemistry 22: 289, 1915.

Fig. 2

Colonies on Czapek medium growing rapidly, 30-50 $\mathrm{mm}$ in 7 days, spreading, velvety, white with conidial masses breaking off in crusts when the culture is jarred, cultures have a silky appearance when viewed under the stereo microscope, dull green or olive green at the centre, with margins shading through pale blue-green to white, exudate and soluble pigment lacking, reverse pale green to yellowish green. Conidial heads irregularly biverticillate. Conidiophores smooth, $200-400 \times 3-3.5 \mu \mathrm{m}$ long. Metulae appressed, in verticils of $2-4,15-25 \times 3.5-4.5 \mu \mathrm{m}$. Phialides in verticils of 6-10, acerose, $10-15 \times 3-3.5 \mu \mathrm{m}$. Conidia elliptical, smooth, very large, 5-5.5 × 3-3.5 $\mu \mathrm{m}$.

Cladosporiumcolocasiae Sawada, Journal of the Natural History Society of Taiwan (Formosa) 25: $125,1916$.

Fig. 3

Colonies on Czapek medium slow growing, zonate, velvety, and uniformly green. Conidiophores on the host conspicuous, mononematous, erect, straight or slightly curved, unbranched, 100-160 $\times 5-6 \mu \mathrm{m}$, arising from the mycelium, solitary or with 2-3 arising from one point, pale to mid-brown, smooth, septate, with terminal and intercalary nodes $8-10 \mu \mathrm{m}$ wide. Conidiogenous cells terminal and swollen becoming intercalary and forming the nodes as the conidiophore elongates. Conidia in branched chains, brownish green, smooth, \pm cylindrical with rounded ends, often constricted in the middle, with protuberant scars at each end, 15-25 $\times 6-8 \mu \mathrm{m}$, 3-4 septate and with several apical to subapical conidiogenous sites when located at the base of a chain, 1-3 septate when located at the apex of a chain. Conidial development initiation holoblastic, in acropetal chains which are branched towards the base, arising from conidiogenous cells which proliferate sympodially; secession schizolytic, leaving a thickened, pigmented and usually protuberant scar.

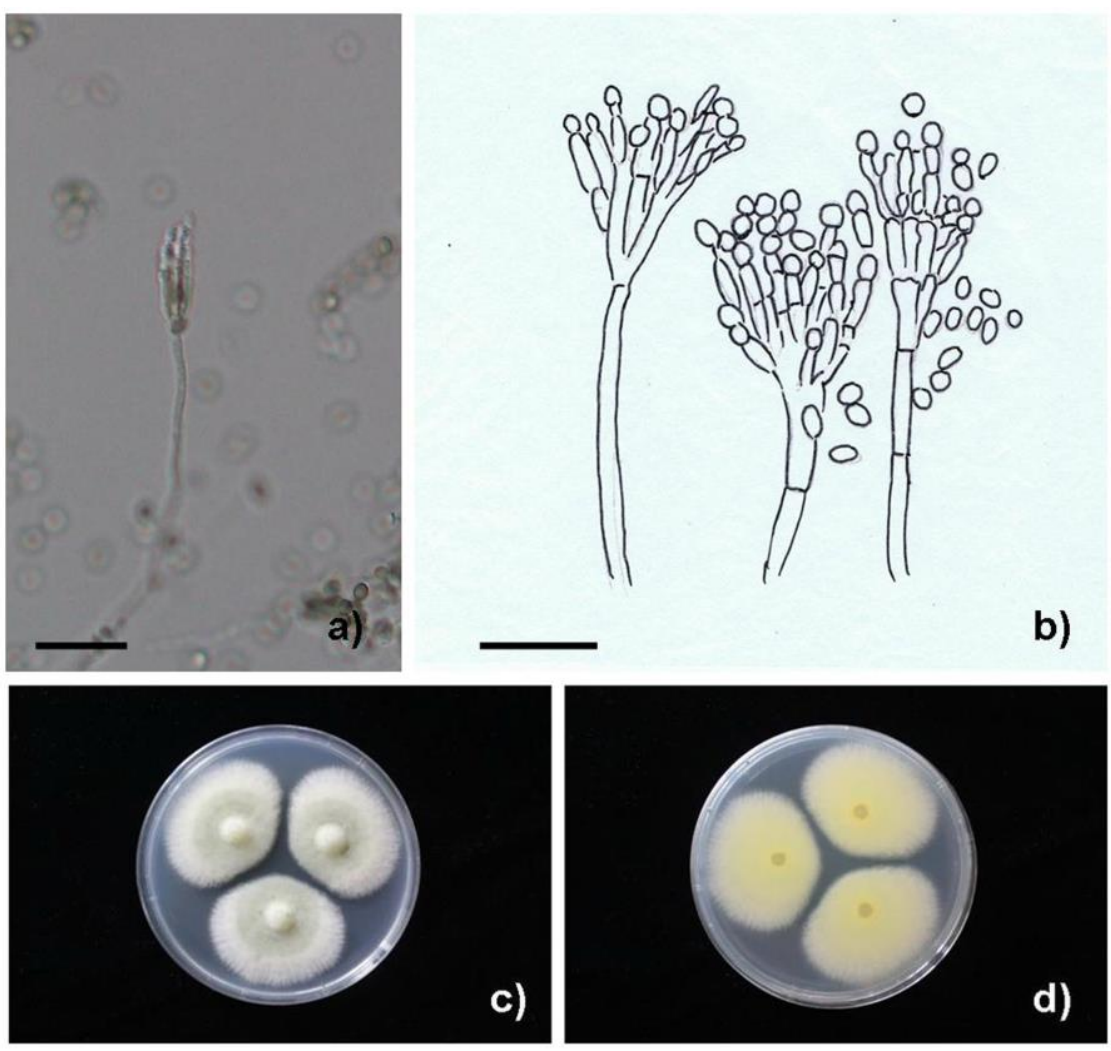

Fig. 2 - Morphological characters and line drawing of Penicillium oxalicum a) and b) Phialides, conidiophores and conidia c) and d) Front and back of colonies on Czapek medium. Bars $=10 \mu \mathrm{m}$. 

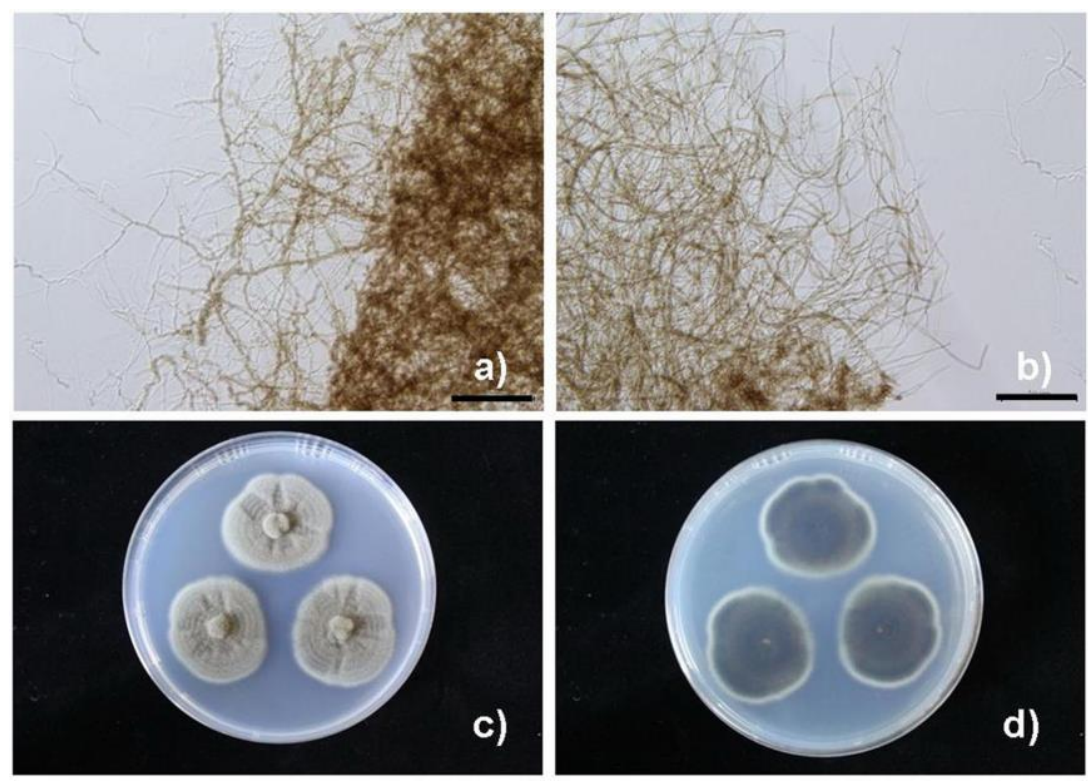

Fig. 3 - Morphological characters of Cladosporium colocasiae a) and b) Mycelia green, velvety and did not produced conidiophore c) and d) Front and back of colonies on Czapek medium. Bars = $100 \mu \mathrm{m}$.

\section{Discussion}

Indoor air in the Gross Anatomy Laboratory showed several types of fungi. Seventeen species are reported. Among them, two species of airborne fungi were found on formalin-fixed human cadavers. This result indicated that some airborne fungi have the high ability to grow and cause contamination, especially Penicillium oxalicum and Cladosporium colocasiae. Previous research in the identification of fungi in formalin-fixed or paraffin-embedded material used antisera originally developed for use in immuno-diffusion assays. They found Aspergillus, Blastomyces, Coccidioides and Histoplasma (Reed et al. 1993). Moreover, Penicillium sp., Chrysonilia sitophila and Trichoderma sp. were found on formalin-fixed human cadavers at the Division of Anatomy, Department of Preclinical Science, Faculty of Medicine, Thammasat University, Thailand (Lakchayapakorn et al. 2008) and Elsebai et al. (2002) found Aspergillus, Penicillium, Trichophyton, Epidermophyton and Cryptococcus on formalin-fixed cadavers at College of Medicine, University of Al-Anbar, Iraq. From our results, we found Cladosporium, which is the first report of this genus on formalin-fixed human cadavers.

Main factors leading to fungal contamination in the Gross Anatomy Laboratory are room humidity, concentration of airborne fungal spores and period of time to fungal inoculation. Normally, $10 \%$ formalin or $4 \%$ formaldehyde in water solution is used for prevent the contamination of microorganisms. Furthermore, formalin-fixed human cadavers are routinely soaked in these sanitizers when used for study and research in hospitals and universities. Therefore, the presence of airborne fungi on formalin-fixed human cadavers could be hazardous and lead to a dangerous risk exposure for instructors.

To prevent further fungal growth there is a need for a better fixative with anti-fungal properties that is safe to use. Fixation methods fall in two classes: cross-linking agents and organic solvents. The result of adding a fixative, such as, formalin to embalming fluid is to react with proteins to create "cross-links". These "cross-links" cause the firmness of embalmed tissue and inactivate the enzymes that are responsible for post-mortem autolytical processes. Formalin acts as a high-level germicide (Demiryürek et al. 2002). One report has suggested that formalin concentration for preventing fungal growth should not be less than 4\% (5-7.5\%) (Kalanjati et al. 2012). Natekar \& Desouza (2007) attempted to optimize the ratio of formalin-fixed human cadaver in preventing decomposition. It was observed that $15 \%$ formalin was very effective in prevention of growth of bacteria, fungi and also decay and discoloration. 


\section{Remarks}

In this research, the cadavers were from people who donated their bodies for medical research at Siriraj Hospital and completed a Declaration of Bequest to Srinakharinwirot University, and their wishes were approved by their next of kin. The fungal collection arising from human cadavers received permission from the Dean of Department of Health Promotion, Faculty of Health Science, Srinakharinwirot University.

\section{Acknowledgements}

This work was financial supported by Department of Health Promotion, Faculty of Health Science, Srinakharinwirot University and National Center for Genetic Engineering and Biotechnology (BIOTEC). We would like to gratefully thank Prof. E.B. Gareth Jones and Dr. Jennifer Divinagracia Luangsa-ard to review our manuscript and give a valuable suggestion. We are grateful to Prof. Yong Poovorawan for the valuable guidance the scientific ethics to submit this research. Finally, we also thank the Dean of Department of Health Promotion, Faculty of Health Science, Srinakharinwirot University for generosity in this study.

\section{References}

Buzina W, Braun H, Schimpl K, Stammberger H. 2003 -Bipolaris spicifera causes fungus balls of the sinuses and triggers polypoid chronic rhinosinusitis in an immunocompetent patient. Journal of Clinical Microbiology 41(10), 4885-4887.

Corden JM, Millington WM. 2012 - The long-term trends and seasonal variation of the aeroallergen Alternaria in Derby, UK. Aerobiologia 17(2), 127-136.

deHoog GS, Guarro J. 1995 - Atlas of Clinical Fungi, $1^{\text {st }}$ edn. Utrecht/Reus: Centraalbureau voor Schimmelcultures/Universitat Rovirai Virgili.

Demiryürek D, Bayramoglu A, staçelebi S. 2002 - Infective agents in fixed human cadavers: A brief review and suggested guidelines. The Anatomical Record 269(4), 194-197.

Elsebai FH, Abbas A, Mohamed SA. 2002 - Fungi that grow on formalin-fixed cadavers. Saudi Medical Journal 23(7), 871-872.

Fairs A, Agbetile J, Bourne M, Hargadon B, Monteiro WR, Morley JP, Edwards RE, Wardlaw AJ, Pashley CH. 2013 - Isolation of Aspergillus fumigatus from sputum is associated with elevated airborne levels in homes of patients with asthma. Indoor Air. 23(4), 275-284.

Flannigan B. 1997 - Air sampling for fungi in indoor environments. J. Aerosol. Sci. 28(3), 381392.

Gams W, Hoekstra ES, Aptroot A. 1998 - CBS course of mycology, $4^{\text {th }}$ edn. Centraalbureau voor Schimmelcultures, Baarn.

Gedikoglu Y, Gedikoglu G, Berkin G, Ceyhan T, Altinoz MA. 2012 - Employing volcanic tuff minerals in interior architecture design to reduce microbial contaminants and airborne fungal carcinogens of indoor environments. Toxicology and Industrial Health 28(8), 708719.

Hawksworth DL. 1991 - The Fungal Dimension of Biodiversity: Magnitude, Significance, and Conservation. Mycological Res. 95, 641-655.

Ishii K, Hitosugi M, Kido M, Yaguchi T, Nishimura K, Hosoya T, Tokudome S. 2006 - Analysis of fungi detected in human cadavers. Legal Medicine 8,188-190.

Kalanjati VP, Prasetiowati L, Alimsardjono H. 2012 - The use of lower formalin-containing embalming solution for anatomy cadaver preparation. Med J Indones. 21(4), 203-207.

Kiyoshi I, Masahito H, Masahito K, Takashi Y, Nazuko N, Tsuyoshi H, Shogo T. 2006 - Analysis of fungi detected in human cadavers. Legal Medicine 8(3), 188-190.

Kwon-Chung KJ, Bennett JE. 1992 - Medical Mycology, $1^{\text {st }}$ edn. Philadelphia: Lea \& Febiger.

Lakchayapakorn K, Tharasub C. 2008 - Analysis of Fungi that grow on Formaline-Fixed Human Cadavers at Thammasat University. Thammasat International Journal of Science and Technology 13(4), 25-31. 
Natekar PE, Desouza FM. 2007 - Higher concentration of formalin for preservation of cadavers for dissection. Anatomica Karnataka 3(1), 81-87.

Nazim K, Ahmed M, Shaukat SS, Khan MU, Rao TA, Ali QM, Sherwani SK. 2012 - Distribution and diversity of airborne microflora under mangrove forest at Sandspit Area Karachi, Pakistan. Sci., Tech. and Dev. 31(4), 305-311.

Reed JA, Hemann BA, Alexander JL, Brigati DJ. 1993 - Immunomycology: rapid and specific immunocytochemical identification of fungi in formalin-fixed, paraffin-embedded material. J. Histochem. Cytochem. 41,1217-1221.

Samson RA, van der Aa HA, Hoog de GS. 2004 - Centraalbureau voor Schimmelcultures: hundred years microbial resource centre. Studies in Mycology 50, 1-8.

Sharpton TJ, Stajich JE, Rounsley SD, Gardner MJ, Wortman JR, Jordar VS, Maiti R, Kodira CD, Neafsey DE, Zeng Q, Hung CY, McMahan C, Muszewska A, Grynberg M, Mandel MA, Kellner EM, Barker BM, Galgiani JN, Orbach MJ, Kirkland TN, Cole GT, Henn MR, Birren BW, Taylor JW. 2009 - Comparative genomic analyses of the human fungal pathogens Coccidioides and their relatives. Genome Res. 19, 1722-1731.

Sri-indrasutdhi V, Tsui CKM, Chuaseeharonnachai C, Yamaguchi K, Suetrong S, Okane I, Nakagiri A, Boonyuen N. 2015 - Helicocentralis hyalina gen. et sp. nov., an aero-aquatic helicosporous fungus (Leotiomycetes, Ascomycota) in Thailand. Mycological progress 14(10), 81 . 